\section{Moisture Content Measurements of Green Roof Substrates Using Two Dielectric Sensors}

\author{
George Kargas ${ }^{1,3}$, Nikolaos Ntoulas ${ }^{2}$, and Panayiotis A. Nektarios ${ }^{2}$
}

\begin{abstract}
ADDITIONAL INDEX WORDs. permittivity, electrical conductivity, coarse-textured substrates, time domain reflectometry

SUMMARY. Little is known about the accuracy of soil moisture dielectric sensors in coarse-textured root zones and green roof substrates. In the present study, the accuracy of two dielectric sensors of different technologies (frequency domain and time domain dielectric sensor) in measuring moisture content was investigated in six coarse-textured green roof substrates. Calibration equations were developed for both sensors, and the effect of electrical conductivity (EC) on substrate moisture content calculation was determined. It was found that for frequency domain sensor the relationship between dielectric permittivity square root $(\sqrt{\varepsilon})$ and actual substrate moisture content $\left(\theta_{\mathrm{m}}\right)$ was strongly linear for all tested substrates. However, for each substrate a distinct specific calibration equation of $\sqrt{\varepsilon}-\theta_{\mathrm{m}}$ was required. The correlation between substrate permittivity and EC was linear for frequency domain sensor for all moisture levels ( $0 \%$ to $35 \%)$. In the case of time domain sensor, each green roof substrate was also described from a different calibration curve between actual substrate moisture content and period of time that was recorded by the device. It was found that their relationship was quadratic for all substrates. In addition, time domain sensor output responded in a quadratic manner to increasing levels of EC. This response was found to interact with actual substrate moisture content as well. It was concluded that the most reliable results for moisture content determination of the coarse-textured green roof substrates were obtained by substrate-specific calibration curves for both dielectric sensors.
\end{abstract}

$\longrightarrow$ urrently several nondestructive, indirect methods for measurement of moisture $(\theta)$ in porous media have been developed. These methods include neutron thermalization (Greacen, 1981), time domain reflectometry [TDR (Topp et al., 1980)], electrical capacitance (Fares and Polyakov, 2006), and others (Bittelli, 2011). Time domain reflectometry is generally regarded as the most accurate electronic technique for determining substrate moisture content (Noborio et al., 1994; Robinson et al., 2003). Its method is based on the measurement of electric pulses travel time along a waveguide, which is directly related to substrate dielectric permittivity $(\varepsilon)$. Water has a much greater value of dielectric permittivity $(\varepsilon=80)$ compared with air $(\varepsilon=1)$ or soil solids $(\varepsilon=3-7)$ and thus the

This article is a portion of a $\mathrm{PhD}$ dissertation to be submitted by N. Ntoulas.

${ }^{1}$ Laboratory of Agricultural Hydraulic, Department of Natural Resources Management and Agricultural Engineering, Division of Water Resources Management, Agricultural University of Athens, Iera Odos 75, Athens 11855, Greece

${ }^{2}$ Laboratory of Floriculture and Landscape Architecture, Department of Crop Science, Agricultural University of Athens, Iera Odos 75, Athens 11855, Greece

${ }^{3}$ Corresponding author. E-mail: kargas@aua.gr measured permittivity is primarily a function of porous media moisture content (Seyfried and Murdock, 2001).

However, the high cost of TDR and difficulties associated with the required waveform analysis have led to the development of alternative dielectric sensors that also use substrate dielectric properties to determine moisture content (Seyfried and Murdock, 2004). Capacitance and frequency techniques offer an excellent alternative to TDR due to their lower cost, capacity for continuous monitoring and data logging, repeatability, and applicability to a wide range of porous media (Dean et al., 1987; Kargas et al., 2011 ; Kargas and Soulis, 2012). Most of the reports that describe TDR method and other dielectric sensors are field studies and only recently have researchers explored their use in soilless and coarse-textured substrates (Morel and Michel, 2004; Nemali et al., 2007; Scoggins and van Iersel, 2006; van Iersel et al., 2011). In the case of TDR, it has been shown that permittivity can be related to porous media moisture content with reasonable accuracy for a wide variety of soils using a single calibration equation developed by Topp et al. (1980). Alternatives to empirically derived calibrations are often based on dielectric mixing models (Roth et al., 1990). Ferre and Topp (2000) reviewed the application of mixing models for moisture content determination and showed that a "square root" mixing model is equivalent to a linear relationship between square root of permittivity and moisture content.

In general, a linear relationship between moisture content and square root of permittivity has been observed in several studies for inorganic soils using commercial sensors (Kargas et al., 2011; Seyfried and Murdock, 2004). In contrast to inorganic soils, the use of dielectric sensors in organic media has revealed that calibration parameters can vary considerably, which is not surprising considering the wide range of these substrate properties. Thus, dielectric sensors generally require substrate-specific calibrations due to the different dielectric properties of the substrates that affect sensor performance (van Iersel et al., 2011; Yoshikawa et al., 2004). This has led researchers to investigate and determine the most suitable calibration equations for each sensor and substrate type (Morel and Michel, 2004).

Substrate moisture content is the major factor affecting the dielectric permittivity of a soilless substrate. However, other substrate-related factors such as EC, temperature, and bulk density can cause dielectric loss and affect the permittivity of a substrate (Nemali et al., 2007). Robinson et al. (1999) reported that TDR

\begin{tabular}{llll}
\hline $\begin{array}{l}\text { Units } \\
\begin{array}{l}\text { To convert U.S. to SI, } \\
\text { multiply by }\end{array}\end{array}$ & U.S. unit & Sl unit & $\begin{array}{l}\text { To convert SI to U.S., } \\
\text { multiply by }\end{array}$ \\
\hline 29.5735 & $\mathrm{fl} \mathrm{oz}$ & $\mathrm{mL}$ & 0.0338 \\
2.54 & inch(es) & $\mathrm{cm}$ & 0.3937 \\
25.4 & inch(es) & $\mathrm{mm}$ & 0.0394 \\
16.3871 & inch & $\mathrm{cm}^{3}$ & 0.0610 \\
1 & $\mathrm{mmho}^{3} \mathrm{~cm}$ & $\mathrm{dS} \cdot \mathrm{m}^{-1}$ & 1 \\
$\left({ }^{\circ} \mathrm{F}-32\right) \div 1.8$ & ${ }^{\circ} \mathrm{F}$ & ${ }^{\circ} \mathrm{C}$ & $\left({ }^{\circ} \mathrm{C} \times 1.8\right)+32$
\end{tabular}


overestimated water content in saline soils due to the overestimation of dielectric permittivity. The newly developed sensors received little or no attention regarding salinity effect on the estimation of permittivity, since it was implicitly assumed that these dielectric devices could perform more or less in a similar manner compared with TDR. Thus, substratespecific calibrations are recommended by most dielectric sensor manufacturers to achieve maximum accuracy of substrate moisture content determination. Although in situ calibration has been attempted, dielectric sensor calibration is mostly performed in laboratory conditions due to the much easier calibration of sensors for a wide range of moisture content. There are two different calibration approaches. The first one uses soil samples in cells with various predetermined moisture regimes, which are assumed uniform throughout the volume of the cells, and a relationship between permittivity and actual moisture content $\left(\theta_{\mathrm{m}}\right)$ is obtained. This approach could not guarantee a constant bulk density, it is time consuming, and it can give limited $\varepsilon-\theta_{\mathrm{m}}$ data points (Seyfried et al., 2005). The second approach is the upward infiltration method proposed by Young et al. (1997), which is relatively rapid and provides more data within the full range of the actual substrate moisture content.

Two moisture sensors have recently become available: 1) the frequency domain dielectric sensor (WET-2 sensor; Delta-T Devices, Cambridge, UK) and 2 ) the time domain dielectric sensor (TDR300; Spectrum Technologies, Plainfield, IL). Due to their reduced rod length, both frequency domain $(6.8 \mathrm{~cm}$ rod length) and time domain sensors (rod length varying from 3.8$20 \mathrm{~cm}$ ) are appropriate for determining moisture content in shallow green roof substrates.

To date, both sensors have not been fully investigated for their capacity to accurately determine moisture content in coarse-textured substrates such as those used for green roofs. Green roof substrates comprised coarse-textured substances to fulfill several criteria such as to maintain adequate moisture for plant growth, to facilitate the quick removal of excess water, to provide support and anchoring of the plants, to provide nutrients, and to possess a $\mathrm{pH}$ and $\mathrm{EC}$ appropriate for plant growth [Forschungsgesellschaft Landschaftsentwicklung Landschaftsbau (FLL), 2008; Getter and Rowe, 2006]. In addition to the above-mentioned criteria, green roof substrates must have reduced weight, which could be accomplished both by the use of lightweight materials and by substrate depth reduction. Thus, several lightweight materials have been used as green roof substrate constituents including pumice (Nektarios et al., 2011); expanded shale, slate, and clay (Beattie and Berghage, 2004; Rowe et al., 2006); perlite (Kotsiris et al., 2012); and others. These materials are coarse textured with most particles having a diameter range from 0.5 to $16 \mathrm{~mm}$ to comply with FLL guidelines (2008). Despite having common coarse-textured characteristics, these materials have different water absorbance and release capacity based on whether they possess or lack internal porosity as well as on the type of internal porosity.

Even though the formulaic concept of extensive green roofs involves irrigation only during plant establishment (FLL, 2008), there is a new trend concerning an "adaptive approach" that aims to use extensive green roof advantages in Mediterranean and other semiarid climates of the globe (Kotsiris et al., 2012; Ntoulas et al., 2012). In the adaptive approach, carefully planned and controlled irrigation is necessary to permit plant growth when the harsh climatic conditions of semiarid regions are combined with shallow extensive green roof substrates. As a result, the accurate moisture content measurement is significant to determine timely application of irrigation and drainage capacity of green roof systems.

Thus, the main objective was to develop calibration equations of frequency and time domain dielectric sensors for determining moisture content in green roof substrates. More specifically, the goals were 1) to evaluate frequency domain sensor performance in measuring moisture content in different coarse-textured green roof substrates using manufacturer's calibration equations and to examine the reliability of the twopoint specific calibration equation; 2) to determine time domain sensor response under increasing green roof substrates moisture content due to the lack of calibration provided by the manufacturer for these types of porous substrates; 3 ) to determine whether time domain and frequency sensor specific calibrations varied with different green roof substrates; 4) to investigate the effect of EC on both sensor outputs. The result from such a detailed evaluation of these two sensors is to assure their improved use in future irrigation programs monitoring of coarse-textured porous substrates.

\section{Materials and methods Formulation of the green roof substrates and determination of their physical and chemical characteristics}

The green roof substrates consisted of locally available materials and were formulated by hand mixing of various organic (peat and compost) and inorganic (sandy loam soil, pumice, perlite, and zeolite) components (Table 1). The formulated substrates were characterized by a constant ratio of organic to inorganic components ( $80 \%$ inorganic, $20 \%$ organic), while the proportion of each inorganic constituent varied between substrates.

The sandy loam soil had $77.0 \%$ sand, $7.8 \%$ silt, $15.2 \%$ clay, and an organic matter of $0.703 \% \mathrm{w} / \mathrm{w}$ by loss on ignition, a $\mathrm{pH}$ of 8.63, and an EC of $0.08 \mathrm{dS} \cdot \mathrm{m}^{-1}$. Pumice had a granulometry of 0.05 to $8 \mathrm{~mm}$ (LAVA; Mineral \& Quarry, Paiania, Greece). Zeolite was clinoptilolite with a granulometry of 0.8 to $2.5 \mathrm{~mm}$ ( $\mathrm{S} \& \mathrm{~B}$ Industrial Minerals, Kifisia, Greece), whereas perlite (Perloflor; Isocon AE, Agios Ioannis Rentis, Greece) had a particle distribution of 0.25 to $5 \mathrm{~mm}$. The compost was composed of straw, sawdust, yard waste (clippings and wood chips) and dairy cow, horse and chicken manure and had a $\mathrm{pH}$ of 8.6 and an EC of $5 \mathrm{dS} \cdot \mathrm{m}^{-1}$. Peat was a sphagnum peat with an organic matter of $90 \%$ by weight and a corrected $\mathrm{pH}$ of 5.5. For each organic component, three inorganic compositions were formulated resulting in six different green roof substrates (Table 1).

\section{Frequency domain dielectric sensor}

The WET-2 sensor is a relatively new and inexpensive frequency domain dielectric soil moisture sensor. The probe consists of three metal rods of $6.8 \mathrm{~cm}$ long and $3 \mathrm{~mm}$ diameter 
Table 1. Inorganic and organic constituents of six green roof substrates and their physical and chemical analyses.

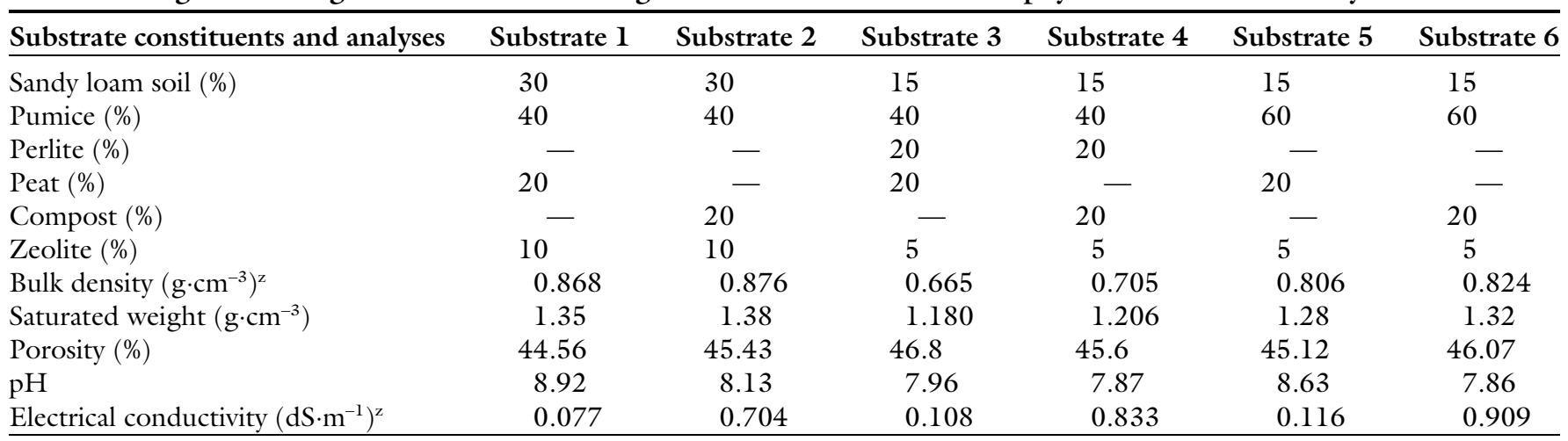

${ }^{2} 1 \mathrm{~g} \cdot \mathrm{cm}^{-3}=0.5780 \mathrm{oz} \cdot \mathrm{inch}^{-3}, \mathrm{ldS} \cdot \mathrm{m}^{-1}=1 \mathrm{mmho} / \mathrm{cm}$.

that are spaced $1.5 \mathrm{~cm}$ apart. The whole central rod is covered by a coating material except for the tip, and it is used to obtain the soil temperature. The sensor is typically connected to an $\mathrm{HH} 2$ moisture meter, which supplies power to the sensor and measures the returned output signal voltage (Delta-T Devices, 2005). Sample size is cylindri$\mathrm{cal}, 6.8 \mathrm{~mm}$ long, and $10 \mathrm{~cm}$ diameter, with an approximate sample volume of $500 \mathrm{~mL}$. The sensor probe measures capacitance $(C)$ and conductance $(G)$ of the substrate between the rods at 20 $\mathrm{MHz}$. The value of permittivity is determined from capacitance using an internal calibration file, and then moisture content is calculated using the following calibration equation:

$$
\theta=\frac{\sqrt{\varepsilon}-\alpha_{0}}{\alpha_{1}}
$$

where $\alpha_{0}$ and $\alpha_{1}$ are substrate dependent. Values of $\alpha_{0}$ and $\alpha_{1}$ as suggested by the manufacturer are provided in Table 2 .

\section{Time domain dielectric sensor}

TDR300 sensor also uses the fact that water dielectric permittivity is much greater than air and soil solids to determine moisture content of substrates either in situ or in the laboratory. It is equipped with two stainless steel rods that act as wave guides. The electronics embedded in the probe send a wave signal toward the rods that travels the whole length of the rods and is partially reflected when it reaches the interface between the rod tip and the soil. The data output is provided as period of time $(T)$, which is inversely related to the number of reflections per second. The signal is transformed into a square wave output with a frequency proportional to moisture content. The period of time increases accordingly to the increase of the porous medium moisture content. The sampling volume is an elliptical cylinder that extends $\approx 3 \mathrm{~cm}$ out from the rods. Time domain sensor has internal calibrations between moisture content and period of time only for "standard" and "high-clay" soil types (Spectrum Technologies, 2009). Therefore, there is a gap concerning time domain sensor calibration in coarsetextured substrates. Based on the manufacturer's manual, high amounts of clay or increased EC $\left(\mathrm{EC}>2 \mathrm{dS} \cdot \mathrm{m}^{-1}\right)$ will attenuate the high-frequency signal and affect the reading displayed by time domain sensor. Similarly, very high organic matter content will affect the readings. The manufacturer does not provide the operation frequency of the time domain sensor.

For maximum accuracy, it is advised by the manufacturer to perform a soil-specific calibration rather than using the two internal soil calibrations of time domain sensor ("standard" or "high clay"). However, because the manufacturer does not provide a physical framework to relate sensor output (period of time) to dielectric permittivity, Eq. [1] cannot be used. In these cases, specific substrate calibration requires the formulation of a relationship between period of time and substrate moisture content. In the present study, two pairs of stainless steel rods of either 7.5 or $12 \mathrm{~cm}$ length were used.

\section{Measurement of moisture content in coarse-textured green roof substrates}

In the present study, the calibration of predetermined moisture regime
Table 2. Values of parameters $\alpha_{0}$ and $\alpha_{1}$ as suggested by the frequency domain dielectric sensor manufacturer.

\begin{tabular}{llc}
\hline Soil type & $\alpha_{0}{ }^{\mathrm{z}}$ & $\alpha_{\mathbf{1}}^{\mathrm{z}}$ \\
\hline Inorganic soils & 1.8 & 10.1 \\
Organic soils & 1.4 & 8.4 \\
Sandy soils & 1.4 & 8.4 \\
Clay soils & 2 & 11 \\
\hline
\end{tabular}

${ }^{2} \alpha_{0}$ and $\alpha_{1}=$ intercept and slope, respectively, of the equation $\sqrt{\varepsilon}=\alpha_{1} \theta+\alpha_{0}$, where $\varepsilon=$ permittivity and $\theta=$ substrate moisture content.

was applied under constant temperature $\left(23 \pm 1{ }^{\circ} \mathrm{C}\right)$. The substrates were oven-dried at $60{ }^{\circ} \mathrm{C}$ for $48 \mathrm{~h}$. A specific mass of each oven-dried substrate was packed in a rectangular polyvinyl chloride box having dimensions of $10 \times 10 \times 15 \mathrm{~cm}$ to achieve a constant bulk density for each material (Table 1). Starting from the oven-dried substrate $(\theta=0)$, deionized water was added to obtain predetermined moisture contents starting from completely dry to saturation in equal moisture content steps, $\Delta \theta=0.05 \mathrm{~cm}^{3} \cdot \mathrm{cm}^{-3}$, taking care to achieve a homogeneous distribution of moisture content in the substrate samples. For this purpose, the box content was hand stirred thoroughly for several minutes and then frequency domain sensor was placed horizontally in the middle of the box. Output readings [moisture content, permittivity, bulk $\mathrm{EC}\left(\mathrm{EC}_{\mathrm{b}}\right)$, and pore water $\mathrm{EC}$ $\left(\mathrm{EC}_{\mathrm{p}}\right)$ ] were taken using the $\mathrm{HH} 2$ moisture meter. Following the frequency domain sensor measurements, time domain sensor was used. Time domain sensor determined the period of time in microseconds and calculated moisture content according to the manufacturer's calibration curve. For 
each substrate and moisture content level, three readings were performed by each sensor. The dry bulk density of each sample was calculated as well, to allow the conversion of moisture content from a mass to a volumetric base.

The above-mentioned methodology provided a sufficient number of permittivity-actual moisture content $\left(\varepsilon-\theta_{\mathrm{m}}\right)$ and actual moisture contentperiod of time $\left(\theta_{\mathrm{m}}-T\right)$ paired readings for frequency domain and time domain sensor, respectively, for all substrates that were examined. The predicted moisture content values obtained from the two sensors were compared with actual moisture content values of each sample.

The specific calibration of frequency domain sensor was based on the following equation, which is expressed in two equivalent forms (Eqs. [1] and [2]) and has been widely applied to TDR and other dielectric sensors (Delta-T Devices, 2005; Ferre and Topp, 2002; Ledieu et al., 1986; Spaans and Baker, 1996; White et al., 1994).

$$
\sqrt{\varepsilon}=\alpha_{1} \theta+\alpha_{0}
$$

The parameters $\alpha_{0}$ and $\alpha_{1}$ depend on the porous material characteristics, and their acquisition can be performed with the following two methods: 1) by performing a linear regression between all pairs of actual substrate moisture content and square root of permittivity (CALAL) and 2 ) by only two independently known values of moisture content and square root of permittivity (CAL). This is usually accomplished with an oven-dried substrate sample, where moisture content $\theta=0$, and therefore the value of $\alpha_{0}$ is readily obtained by Eq. [1]. The second moisture content value was taken at or near saturation to cover the full substrate moisture range (Seyfried et al., 2005). The value of $\alpha_{1}$ is then given by Eq. [3].

$$
\alpha_{1}=\frac{\sqrt{\varepsilon}-\sqrt{\varepsilon_{, \theta=0}}}{\theta}
$$

Using the above methods (linear regression calibration using all data points-CALAL, and the two-point calibration-CAL), the specific calibration equations for each porous material were produced.

\section{EC effects on dielectric sensor responses}

Measurements IN AQUeOUS SOLUTIONS WITH INCREASING EC. Before using the dielectric sensors in green roof substrates, preliminary tests were performed to determine the sensor accuracy and sensitivity to EC using 25 different aqueous solutions of sodium chloride $(\mathrm{NaCl})$ that ranged in EC from 0 to $10 \mathrm{dS} \cdot \mathrm{m}^{-1}$. As the EC of the solutions was increasing, dielectric permittivity and period of time were determined for frequency and time domain sensor, respectively. For time domain sensor, the measurements were performed with both 7.5 - and $12-\mathrm{cm}$ rod lengths.

Measurements in substrates WITH INCREASING EC. The effect of EC on probe outputs was investigated in a single green roof substrate (substrate 5; Table 1). Solutions with increasing EC were used to hydrate the green roof substrates instead of deionized water. The EC of the solutions added into the substrate were $0.5,1.5,2.5$, and $3.5 \mathrm{dS} \cdot \mathrm{m}^{-1}$. For each actual substrate moisture content and EC level, permittivity, moisture content, $\mathrm{EC}_{\mathrm{b}}$, and $\mathrm{EC}_{\mathrm{p}}$ were determined with frequency domain sensor. Similarly for time domain sensor, the period of time was determined for each actual moisture content and EC level.

\section{Statistical analyses}

For each substrate and moisture content, three measurements were performed with each dielectric sensor in different sample locations. For each green roof substrate, a calibration equation was derived by regressing the plotted data. The dependent variable was substrates' moisture content, and the independent variable was square root of permittivity and period of time for frequency and time domain sensors, respectively. Regression was performed using JMP (version 8; SAS Institute, Cary, NC). For frequency domain sensor, the evaluation of calibration methodologies efficiency was determined using rootmean-square error (RMSE) for total data points (CALAL), two-point (CAL) calibration, and manufacturer calibration methodology. The same procedure was not applicable for time domain dielectric sensor since its response was quadratic.

\section{Results and discussion Sensors calibration}

FREQUENCY DOMAIN DIELECTRIC SENSOR. Our results indicated that the relationship between square root of permittivity and actual moisture content was strongly linear with a high $R^{2}$ $\left(0.982<R^{2}<0.993\right)$ for all six substrates (Fig. 1). Therefore, for the green roof coarse-textured substrates, a simple linear relationship can describe the relationship between $\sqrt{\varepsilon}-\theta_{\mathrm{m}}$ as suggested by frequency domain sensor manufacturer for other types of porous media. This relationship has been proven to be effective for other sensors as well (Kargas and Kerkides, 2008; Kargas and Soulis, 2012).

For each substrate, the determined values of parameters $\alpha_{0}$ and $\alpha_{1}$ from the linear regression using either all experimental data (CALAL) or by the two-point calibration (CAL) procedure are presented in Table 3 . It was found that $\alpha_{0}$ and $\alpha_{1}$ values between the two calibration methodologies were similar for all green roof substrates (Table 3 ).

For the estimation of each calibration curve, the RMSE was calculated based on Eq. [4].

$$
\text { RMSE }=\sqrt{\frac{\sum_{\mathrm{i}=1}^{n}\left(\theta_{\mathrm{m}}-\theta\right)^{2}}{n}}
$$

where $\theta_{\mathrm{m}}$ is the actual moisture content, $\theta$ is the predicted value either via soil-specific calibration (CALAL and CAL) or according to the manufacturer calibration, and $n$ is the number of $\theta_{\mathrm{m}}-\theta$ couples.

Our results indicated that the calibration with linear regression using all experimental data (CALAL) resulted in better correlation $(0.008$ $\mathrm{cm}^{3} \cdot \mathrm{cm}^{-3}<$ RMSE $<0.013 \mathrm{~cm}^{3} \cdot \mathrm{cm}^{-3}$ ) compared with the other two calibration methods (Table 3). However, two-point calibration provided adequately reliable results as well $(0.01$ $\mathrm{cm}^{3} \cdot \mathrm{cm}^{-3}<$ RMSE $<0.017 \mathrm{~cm}^{3} \cdot \mathrm{cm}^{-3}$ ) while at the same time it was effortless compared with using all experimental data (Table 3). Therefore, two-point calibration can be used for routine green roof substrate moisture measurements with frequency domain sensor.

For peat-amended green roof substrates, the use of manufacturer calibration that refers to "organic soils" $\left(\alpha_{0}=1.4\right.$ and $\left.\alpha_{1}=8.4\right)$ provided 


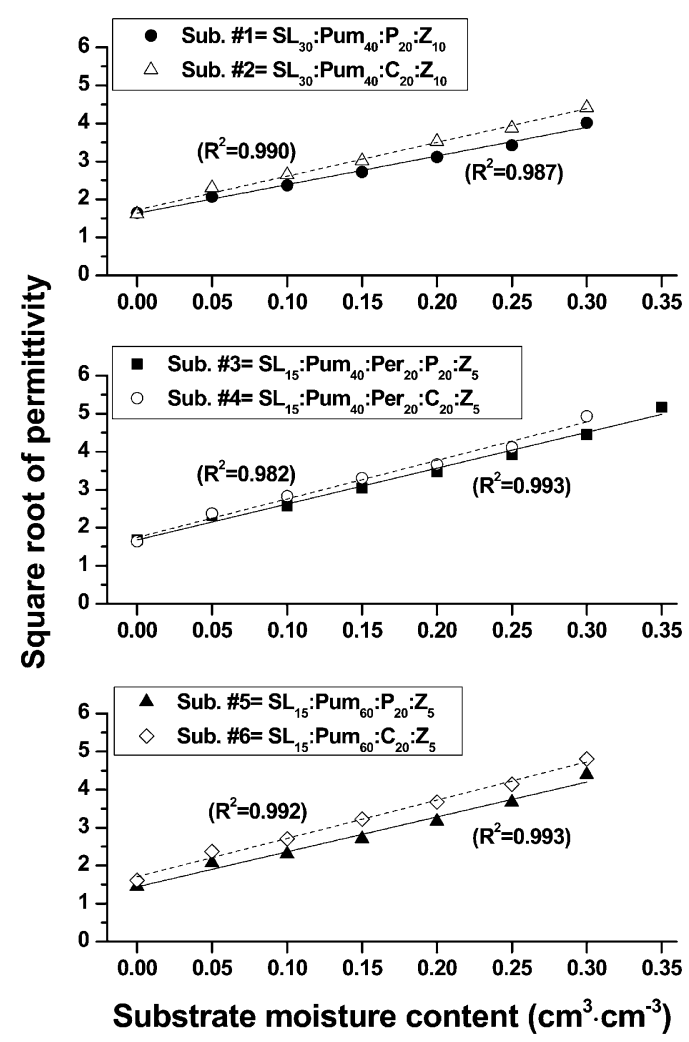

Fig. 1. Relationship between square root of permittivity and substrate actual moisture content for the frequency domain dielectric sensor in six green roof substrates. Data represent the mean of three replications; Sub. = substrate, $\mathrm{SL}=$ sandy loam soil, $\mathrm{Pum}=$ pumice, $\mathrm{Per}=$ perlite, $\mathrm{P}=$ peat, $\mathrm{C}=$ compost, and $\mathrm{Z}=$ zeolite The subscripts indicate the volumetric proportion of each substrate constituent.

Table 3. Parameter and root-mean-square error (RMSE) values for linear regression using all experimental data (CALAL) and two-point (CAL) specific calibration for the frequency domain dielectric sensor. Values of RMSE also are provided for the manufacturer calibration using the "inorganic media" indication of frequency domain sensor.

\begin{tabular}{|c|c|c|c|c|c|c|c|}
\hline \multirow[b]{3}{*}{ Substrate $^{\mathrm{z}}$} & \multirow{2}{*}{\multicolumn{2}{|c|}{ CALAL }} & \multirow{2}{*}{\multicolumn{2}{|c|}{ CAL }} & \multicolumn{3}{|c|}{ RMSE } \\
\hline & & & & & \multirow{2}{*}{$\begin{array}{c}\text { Frequency domain } \\
\text { sensor }\end{array}$} & \multirow[b]{2}{*}{ CALAL } & \multirow[b]{2}{*}{ CAL } \\
\hline & $\alpha_{0}^{y}$ & $\alpha_{1}{ }^{y}$ & $\alpha_{0}$ & $\alpha_{1}$ & & & \\
\hline 1 & 1.68 & 9.42 & 1.67 & 9.23 & 0.026 & 0.011 & 0.012 \\
\hline 2 & 1.74 & 10.12 & 1.64 & 10.93 & 0.011 & 0.011 & 0.012 \\
\hline 3 & 1.44 & 9.19 & 1.44 & 9.83 & 0.049 & 0.013 & 0.017 \\
\hline 4 & 1.70 & 10.1 & 1.61 & 10.63 & 0.027 & 0.010 & 0.011 \\
\hline 5 & 1.63 & 7.53 & 1.64 & 7.90 & 0.060 & 0.008 & 0.012 \\
\hline 6 & 1.72 & 8.87 & 1.61 & 9.33 & 0.028 & 0.008 & 0.010 \\
\hline
\end{tabular}

${ }^{z}$ Substrate $\mathrm{l}=\mathrm{SL}_{30}: \mathrm{Pum}_{40}: \mathrm{P}_{20}: \mathrm{Z}_{10}$, substrate $2=\mathrm{SL}_{30}: \mathrm{Pum}_{40}: \mathrm{C}_{20}: \mathrm{Z}_{10}$, substrate $3=\mathrm{SL}_{15}: \operatorname{Pum}_{40}: \mathrm{Per}_{20}: \mathrm{P}_{20}: \mathrm{Z}_{5}$, substrate $4=\mathrm{SL}_{15}: \operatorname{Pum}_{40}: \operatorname{Per}_{20}: \mathrm{C}_{20}: \mathrm{Z}_{5}$, substrate $5=\mathrm{SL}_{15}: \mathrm{Pum}_{60}: \mathrm{P}_{20}: \mathrm{Z}_{5}$, substrate $6=\mathrm{SL}_{15}: \operatorname{Pum}_{60}: \mathrm{C}_{20}: \mathrm{Z}_{5}$, where $\mathrm{SL}=$ sandy loam soil, $\mathrm{Pum}=$ pumice, $\mathrm{P}=$ peat, $\mathrm{Per}=$ perlite, $\mathrm{C}=$ compost, and $\mathrm{Z}=$ zeolite. The subscripts indicate the volumetric proportion of each substrate constituent.

${ }^{y} \alpha_{0}$ and $\alpha_{1}=$ intercept and slope, respectively, of the equation $\sqrt{\varepsilon}=\alpha_{1} \theta+\alpha_{0}$, where $\varepsilon=$ permittivity and $\theta=$ substrate moisture content.

better RMSE values $(0.017$ and 0.049 $\mathrm{cm}^{3} \cdot \mathrm{cm}^{-3}$, respectively) compared with the "inorganic soils" calibration $(0.026$ and $0.060 \mathrm{~cm}^{3} \cdot \mathrm{cm}^{-3}$, respectively). In contrast for substrates containing compost as an organic source instead of peat, the manufacturer's calibration that referred to "inorganic porous media" $\left(\alpha_{0}=1.8\right.$ and $\left.\alpha_{1}=10.1\right)$ provided a better RMSE (0.011 $\mathrm{cm}^{3} \cdot \mathrm{cm}^{-3}<$ RMSE $<0.028 \mathrm{~cm}^{3} \cdot \mathrm{cm}^{-3}$ ) compared with "organic soils" calibration $\left(0.048\right.$ and $0.075 \mathrm{~cm}^{3} \cdot \mathrm{cm}^{-3}$, respectively). These differences highlighted the absolute need for substrate-specific calibration, by obtaining specific values for parameters $\alpha_{0}$ and $\alpha_{1}$ due to the particular characteristics of each substrate.

Increasing pumice proportion from $40 \%$ to $60 \%$, while the proportion of inorganic-organic components remained constant at an 80:20 ratio, reduced the values of parameter $\alpha_{1}$ in both substrates (substrates 5 and 6 ) that contained peat and compost $[7.53$ and 8.87 , respectively (Table 3 )]. In contrast, $\alpha_{0}$ values were almost similar between the substrates that contained either $60 \%$ or $40 \%$ pumice except for substrate 3 . It is therefore clear that the use of frequency domain sensor for determining moisture content of a green roof substrate demands determination of the exact values of parameters $\alpha_{0}$ and $\alpha_{1}$. These results seem to contradict to those of Nemali et al. (2007) who evaluated different dielectric sensors. The researchers evaluated dielectric sensors in nine substrates with $60 \%$ organic and $40 \%$ inorganic components and concluded that regardless of the type of organic and inorganic components used in preparing a substrate, a single calibration equation could be used to estimate substrate moisture content. This contradiction compared with our study might be due to the different sensor operating frequencies (70 and 100 $\mathrm{MHz}$ ) used by Nemali et al. (2007) compared with the frequency domain sensor $(20 \mathrm{MHz})$ that was used in our study.

It should also be noted that $\mathrm{EC}_{\mathrm{p}}$ of the substrates as measured by frequency domain sensor and based on the model of Hilhorst (2000) provided values ranging from 1.44 to $2.82 \mathrm{dS} \cdot \mathrm{m}^{-1}$. The substrates containing compost exhibited higher $\mathrm{EC}_{\mathrm{p}}$ $\left(2.5 \mathrm{dS} \cdot \mathrm{m}^{-1}<\mathrm{EC}_{\mathrm{p}}<2.82 \mathrm{dS} \cdot \mathrm{m}^{-1}\right)$ compared with those containing peat $\left(1.44 \mathrm{dS} \cdot \mathrm{m}^{-1}<\mathrm{EC}_{\mathrm{p}}<1.77 \mathrm{dS} \cdot \mathrm{m}^{-1}\right)$. However, the calibration equation of compost-amended substrates was unaffected by $\mathrm{EC}_{\mathrm{p}}$ until the limit of $2.82 \mathrm{dS} \cdot \mathrm{m}^{-1}$, which was substantiated by high $R^{2}$ values of the relationship between square root of permittivity and substrate moisture content (Fig. 1).

Time domain Dielectric SENSOR. In contrast to frequency domain sensor, which determines permittivity values, time domain sensor provides the period of time as well as 
moisture content values calculated by an instrument-integrated equation. Thus, the calibration methodology of time domain sensor should differ from that of frequency domain sensor. In such case, the relation between period of time and actual substrate moisture must be investigated for each green roof substrate. It was found that for the same actual moisture content, the period of time was always greater in $12-\mathrm{cm}$ rods compared with $7.5-\mathrm{cm}$ rods (Fig. 2). This was expected since longer waveguides increase travel time of the signal and result in an increased period of time.

For all substrates and both rod lengths, the equation describing the relationship between period of time and substrate moisture content was a second-order polynomial with very high $R^{2}$ (Fig. 2). In contrast, the "standard" manufacturer calibration between moisture content and period of time $(\theta-\mathrm{T})$ was linear with $R^{2}>$ 0.99 in all cases.

It was further investigated whether substrates with the same amount and type of organic matter [e.g., substrates
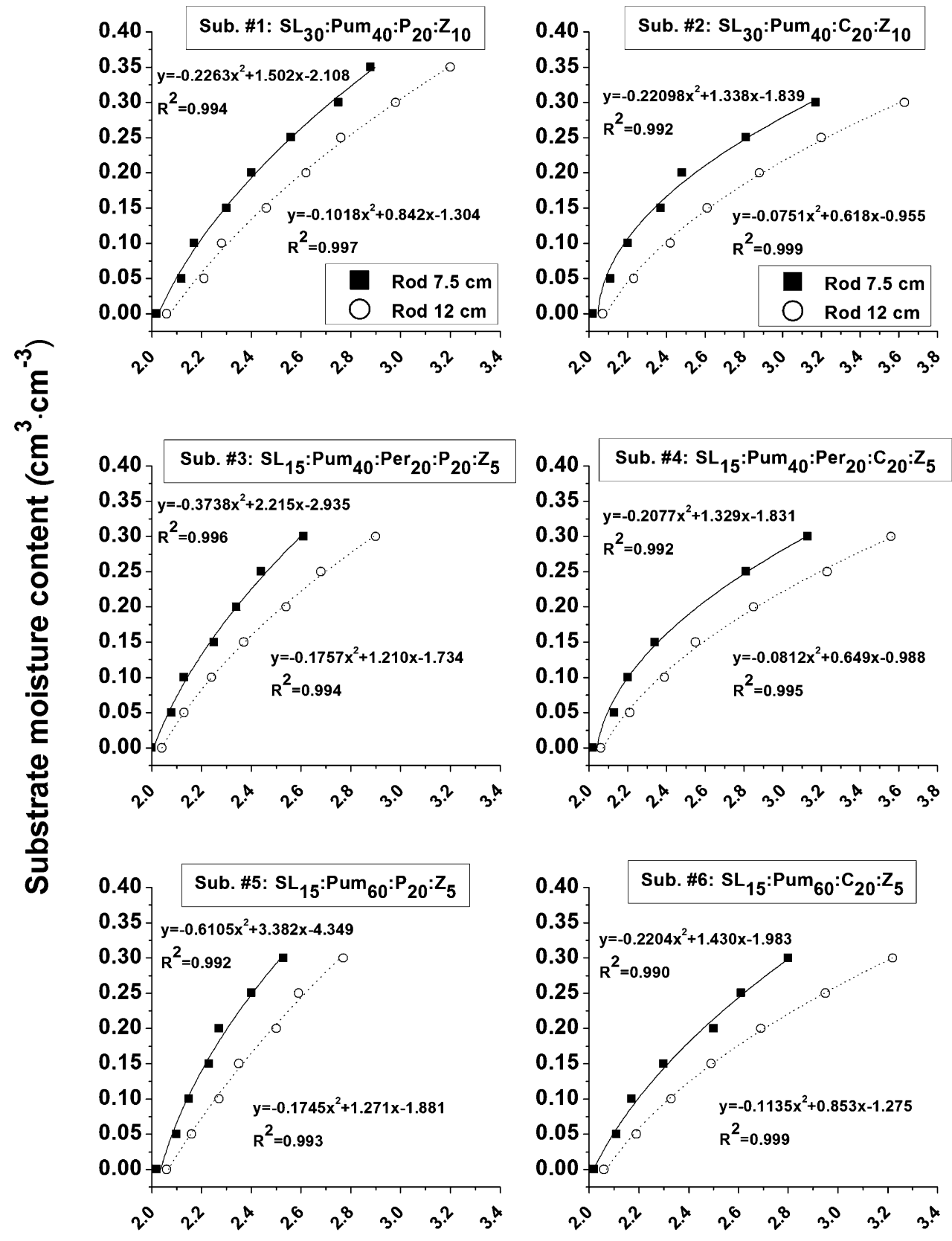

Period of time $\left(10^{-3} \mu \mathrm{s}\right)$

Fig. 2. Relationship between substrate actual moisture content and period of time given by time domain dielectric sensor for six green roof substrates and using two pairs of stainless steel rod lengths of 7.5 or $12 \mathrm{~cm}(2.76$ or 4.72 inches $)$. Data represent the mean of three replications; Sub. = substrate, $\mathrm{SL}=$ sandy loam soil, $\mathrm{Pum}=$ pumice, $\mathrm{Per}=$ perlite, $\mathrm{P}=$ peat, $\mathrm{C}=$ compost, and $\mathrm{Z}=$ zeolite. The subscripts indicate the volumetric proportion of each substrate constituent. 
1,3 , and 5 or substrates 2,4 , and 6 (Table 1)] could be calibrated by a single calibration equation (Fig. 2). It was found that similar to frequency domain, the time domain sensor required a different calibration curve for each substrate. These results agreed with those of Morel and Michel (2004) who evaluated the use of TDR on various substrates types. For example, at $\theta_{\mathrm{m}}=0.2 \mathrm{~cm}^{3} \cdot \mathrm{cm}^{-3}$, the time domain sensor outputs were 2400,2340 , and $2270 \mu$ s for substrates 1,3 , and 5 , respectively (Fig. 2).

To examine the influence of organic amendment source on time domain sensor calibration equation, two substrates with identical inorganic composition [substrates 5 and 6 (Table 1)] that differed only on the organic matter source (either peat or compost) were compared (Fig. 3). It was found that for the same actual moisture content the substrates containing compost provided much larger values concerning the period of time compared with peat-amended substrates. As a consequence, the larger time values in compost-amended substrate 6 caused an overestimation of moisture content, based on manufacturer's "standard" calibration, for moisture content values greater than $0.15 \mathrm{~cm}^{3} \cdot \mathrm{cm}^{-3}$. In contrast for peatamended substrate (substrate 5 ), the manufacturers' standard calibration equation led to an underestimation of moisture content. This response of peat-amended substrate may be attributed to the phenomenon of bound water. In such case, permittivity of the porous medium is lower compared with that of another porous medium, which has the same moisture content but does not exhibit the phenomenon of bound water (Anisko et al., 1994; Dasberg and Hopmans, 1992). As a result, the smaller permittivity of the porous medium led to lower moisture content values. In the case of compostamended substrates, the observed overestimation at moisture contents larger than $0.15 \mathrm{~cm}^{3} \cdot \mathrm{cm}^{-3}$ may be attributed to increased salinity of the substrates (Table 1).

The EC of substrate pore water, calculated by Hilhorst model (2000) for the frequency domain sensor, ranged from 2.5 to $2.82 \mathrm{dS} \cdot \mathrm{m}^{-1}$. These values were greater than the 2 $\mathrm{d} S \cdot \mathrm{m}^{-1}$ threshold and possibly would attenuate the signal and affect the reading displayed by the meter. It might therefore be stated that time domain sensor response was sensitive even at low EC levels $\left(<\mathrm{l} \mathrm{dS} \cdot \mathrm{m}^{-1}\right)$. This may be attributed to particularities of the sensor and thus this sensitivity was investigated further.

\section{Effects of EC on sensor outputs}

EFFECTS OF AQUEOUS SOLUTION

EC ON SENSOR OUTPUTS. Frequency domain sensor permittivity remained relatively stable as EC increased from 0 to $3 \mathrm{dS} \cdot \mathrm{m}^{-1}$ (Fig. $4 \mathrm{~A}$ ). When EC values exceeded the limit of $3 \mathrm{dS} \cdot \mathrm{m}^{-1}$, the dielectric permittivity reduced its values. These results are similar to those reported by Regalado et al. (2007) and contradict the manufacturer's claim that for EC $\leq 6 \mathrm{dS} \cdot \mathrm{m}^{-1}$ there are no noticeable effects of EC on permittivity.

For time domain sensor, the influence of EC exhibited a completely

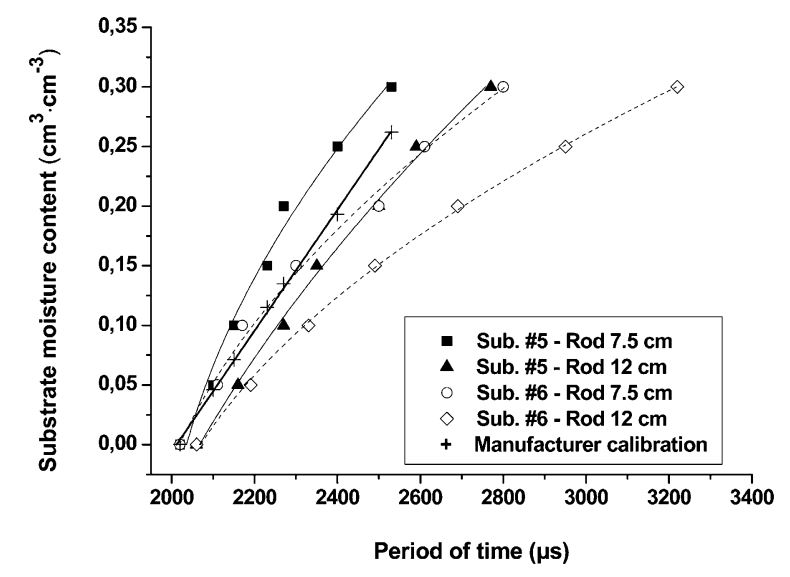

Fig. 3. Relationship between substrate actual moisture content and period of time given by time domain dielectric sensor for substrate $5\left(\mathrm{SL}_{15}: \mathrm{Pum}_{60}: \mathrm{P}_{20}: \mathrm{Z}_{5}\right)$ and substrate $6\left(\mathrm{SL}_{15}: \mathrm{Pum}_{60}: \mathrm{C}_{20}: \mathrm{Z}_{5}\right)$ using two pairs of stainless steel rods of 7.5 or 12 $\mathrm{cm}$ length ( 2.76 or 4.72 inches). The manufacturer calibration is also provided for substrate 5 with $7.5-\mathrm{cm}$ rod length. Data represent the mean of three replications; Sub. = substrate, $\mathrm{SL}=$ sandy loam soil, $\mathrm{Pum}=$ pumice, $\mathrm{P}=$ peat, $\mathrm{C}=$ compost, and $\mathrm{Z}=$ zeolite. The subscripts indicate the volumetric proportion of each substrate constituent.
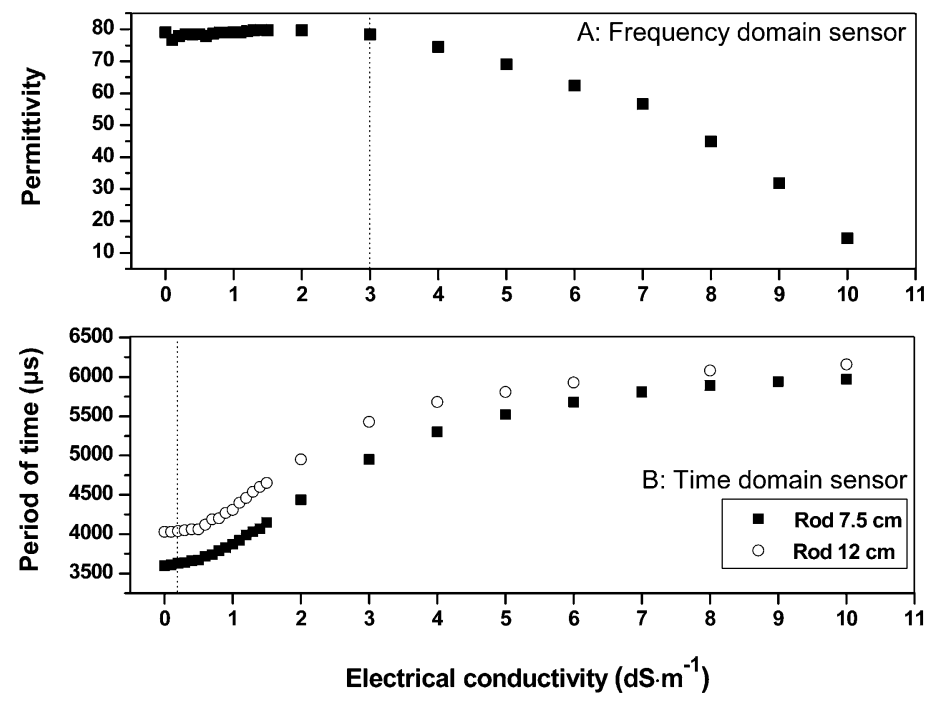

Fig. 4. (A) Permittivity changes in correlation with increasing electrical conductivity (EC) of the aqueous solution for the frequency domain dielectric sensor; (B) Period of time changes in correlation with increasing EC of the aqueous solution for time domain dielectric sensor using two pairs of stainless steel rods of 7.5 or $12 \mathrm{~cm}(2.76$ or 4.72 inches). The dotted lines represent the threshold after which the EC interferes with each sensor output; $1 \mathrm{dS} \cdot \mathrm{m}^{-1}=1 \mathrm{mmho} / \mathrm{cm}$. 
different response compared with frequency domain sensor (Fig. 4B). More specifically, the stepwise increase of EC resulted in increasing period of time from the initial value of $3600 \mu$ s even from EC values as low as $0.2 \mathrm{dS} \cdot \mathrm{m}^{-1}$ for the rods of $7.5 \mathrm{~cm}$ length. Time domain sensor manufacturer manual reports that moisture content indication in distilled water should be within the range of $70 \%$ to $75 \%$ when the length of the rods is $12 \mathrm{~cm}$. Indeed in our study when $12-\mathrm{cm}$ rods were placed in distilled water with $0 \mathrm{dS} \cdot \mathrm{m}^{-1} \mathrm{EC}$, the moisture content was $73.1 \%$ and the corresponding period of time was $4130 \mu$ s. However, at an EC of $10 \mathrm{dS} \cdot \mathrm{m}^{-1}$ the period of time reached $\approx 6000 \mu \mathrm{s}$, which corresponded to an unreal volumetric moisture content of $195 \%$. Thus, it seems that time domain sensor is sensitive to EC increases. Consequently, the increase in period of time due to solution EC resulted in increases in permittivity value (Topp et al., 2000).

From the above-mentioned data, it is obvious that the response of each dielectric sensor to salinity levels was different. This is a rather complicated phenomenon, and it might be affected by individual characteristics of the sensors such as operating frequency, way of inferring with permittivity, and others.

EfFects of substrate EC ON DIELECTRIC SENSORS OUTPUTS. It was found that for frequency domain sensor the relationship between permittivity and EC was linear with an $R^{2}$ greater than 0.91 . The effect of increasing EC on permittivity was small and nearly the same in all substrate moisture levels as indicated by the similar slopes of the lines (Fig. 5). Changes in permittivity with increasing levels of EC under the highest tested substrate moisture level $(\theta=$ $\left.0.3 \mathrm{~cm}^{3} \cdot \mathrm{cm}^{-3}\right)$ corresponded to a maximum moisture content change of $0.032 \mathrm{~cm}^{3} \cdot \mathrm{cm}^{-3}$. Based on all the above it is obvious that frequency domain sensor can be used up to $3.5 \mathrm{dS} \cdot \mathrm{m}^{-1}$ EC by a single calibration equation for routine type measurements.

To compare different responses of the two dielectric sensors under increasing levels of EC, the same investigation was performed for time domain sensor. Time domain sensor output responded in a quadratic fashion to increasing substrate EC (Fig. 6).

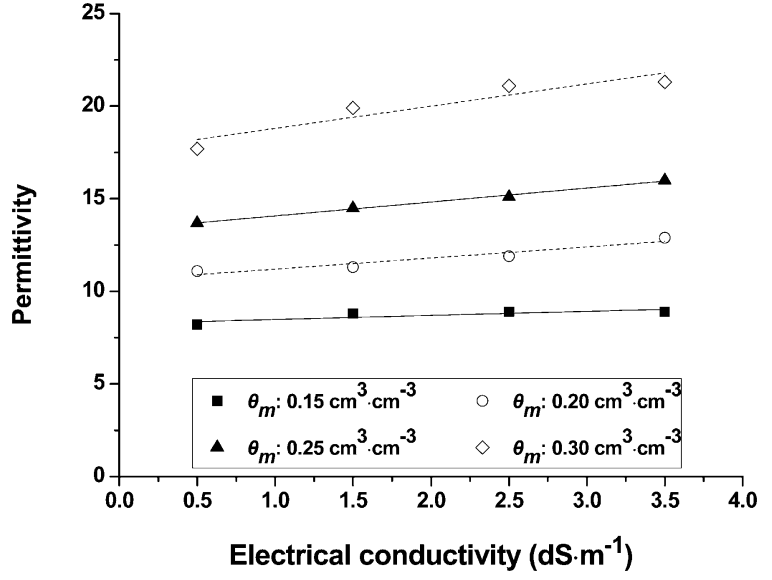

Fig. 5. Frequency domain dielectric sensor outputs as affected by increasing electrical conductivity under different moisture content levels $\left(\theta_{m}\right)$ of substrate $5\left(S_{15}: P_{u_{0}}: P_{20}: Z_{5}\right.$, where $S L=$ sandy loam soil, $P u m=$ pumice, $P$ = peat, $\mathrm{Z}=$ zeolite, and the subscripts indicate the volumetric proportion of each substrate constituent). Data represent the mean of three replications; $1 \mathrm{dS} \cdot \mathrm{m}^{-1}=$ $1 \mathrm{mmho} / \mathrm{cm}$.

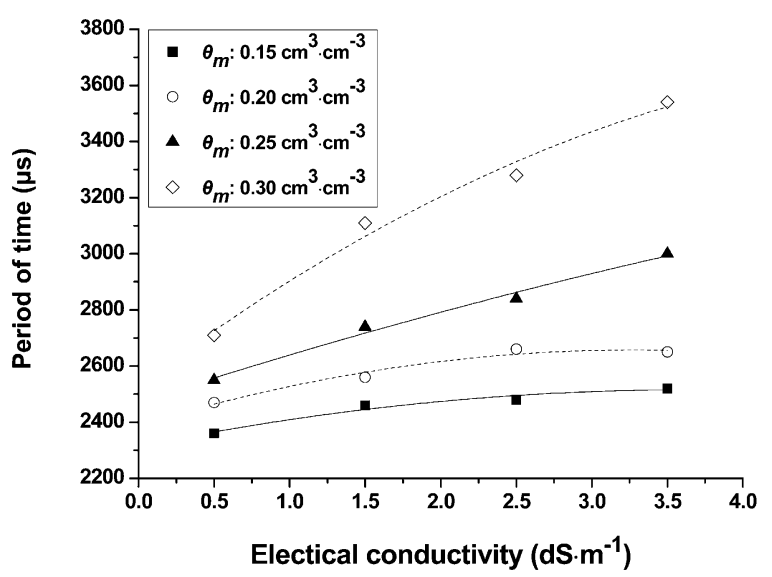

Fig. 6. Time domain dielectric sensor outputs [ rod length of $12 \mathrm{~cm}(4.72$ inches $)$ ] as affected by increasing electrical conductivity under different moisture content levels $\left(\theta_{\mathrm{m}}\right)$ of substrate $5\left(\mathrm{SL}_{15}: \mathrm{Pum}_{60}: \mathrm{P}_{20}: Z_{5}\right.$, where $\mathrm{SL}=$ sandy loam soil, $\mathrm{Pum}=$ pumice, $\mathbf{P}=$ peat, $\mathbf{Z}=$ zeolite, and the subscripts indicate the volumetric proportion of each substrate constituent). Data represent the mean of three replications; $1 \mathrm{dS} \cdot \mathrm{m}^{-1}=$ $1 \mathrm{mmho} / \mathrm{cm}$.

This behavior appeared to be affected by both moisture content and EC levels of the substrate. At lower moisture content $\left(0.15\right.$ and $\left.0.2 \mathrm{~cm}^{3} \cdot \mathrm{cm}^{-3}\right)$, the effect of increasing substrate EC exhibited a smaller impact on time domain sensor outputs. In contrast, at higher actual moisture content $\left(0.3 \mathrm{~cm}^{3} \cdot \mathrm{cm}^{-3}\right)$ the effect of EC increased. For example, in a moisture content of $0.15 \mathrm{~cm}^{3} \cdot \mathrm{cm}^{-3}$ time domain sensor output varied from 2360 to $2520 \mu$ s for EC levels of 0.5 and $3.5 \mathrm{dS} \cdot \mathrm{m}^{-1}$, respectively. In contrast at moisture content of $0.3 \mathrm{~cm}^{3} \cdot \mathrm{cm}^{-3}$ time domain sensor output varied from 2710 to $3540 \mu \mathrm{s}$. It was also observed that for all compost-amended substrates that exhibited increased bulk EC, the overestimation of period of time for the same moisture content occurred from an EC of $1.5 \mathrm{dS} \cdot \mathrm{m}^{-1}$, indicating that the upper EC limit of $2 \mathrm{dS} \cdot \mathrm{m}^{-1}$ reported by the manufacturer was inaccurate for these substrates (Fig. 6).

The sensitivity of time domain sensor to EC and its interaction with moisture content complicated the calibration process significantly. The whole calibration procedure might be facilitated only in those cases where EC of irrigation water is stable, and changes do not occur concerning salt 
concentration of the substrates. In the event that the above-mentioned hypotheses do not hold, then a periodical testing of EC substrate solution would be required along with a new calibration equation. However, when substrate moisture content is small $\left(0.15 \mathrm{~cm}^{3} \cdot \mathrm{cm}^{-3}\right)$ the EC increase does not have a significant impact on time domain sensor output. Since deviations from these conditions (i.e., $\theta>$ $0.15 \mathrm{~cm}^{3} \cdot \mathrm{cm}^{-3}$ ) occur frequently in substrates, time domain sensor requires substrate-specific calibration.

\section{Conclusions}

Our objective was to evaluate the accuracy of frequency and time domain sensors for measuring moisture content of various green roof substrates and to determine the effect of substrate EC on the accuracy of the measured data. Based on the presented and discussed results of the study, the following conclusions were drawn:

1. For frequency domain sensor, the relationship between permittivity square root and actual moisture content was strongly linear with very high $R^{2}$ for all tested substrates. However, for each substrate it was required to obtain specific values for the linear regression equation parameters $\left(\alpha_{0}\right.$ and $\left.\alpha_{1}\right)$. The simplified two-point calibration method for frequency domain sensor provided adequately reliable results in predicting substrate moisture content $(0.01$ $\left.\mathrm{cm}^{3} \cdot \mathrm{cm}^{-3}<\mathrm{RMSE}<0.017 \mathrm{~cm}^{3} \cdot \mathrm{cm}^{-3}\right)$ by demanding less tedious work. Changes of permittivity as EC increased corresponded to a maximum change of moisture content of 0.032 $\mathrm{cm}^{3} \cdot \mathrm{cm}^{-3}$. On the basis of results above, frequency domain sensor can be used up to $3.5 \mathrm{dS} \cdot \mathrm{m}^{-1}$ of $\mathrm{EC}$ by using a single calibration equation.

2 . Time domain sensor also requires a separate calibration curve for each substrate to determine the relationship of actual moisture content and the measured period of time. The relationship between moisture content and period of time was quadratic. In addition, time domain sensor output responded in a quadratic form to increasing levels of EC, which also interacted with substrate moisture content. Thus, time domain dielectric sensor measurements became very doubtful when EC increased in conjunction with increased substrate moisture. In contrast, when moisture content was less than $0.15 \mathrm{~cm}^{3} \cdot \mathrm{cm}^{-3}$, the EC increase had a minor effect, and thus the device could be used for this range of moisture content in routine work.

\section{Literature cited}

Anisko, T., D.S. NeSmith, and O.M. Lindstrom. 1994. Time domain reflectometry for measuring water content of organic growing media in containers. HortScience 29:1511-1513.

Beattie, D.J. and R.D. Berghage. 2004. Green roof media characteristics: The basics. Proc. of 2nd North American Green Roof Conf. Greening rooftops for sustainable communities conference, Portland, OR, 2-4 June 2004. Cardinal Group, Toronto, ON. p. 411-416.

Bittelli, M. 2011. Measuring soil water content: A review. HortTechnology 21:293-300.

Dasberg, S. and J.W. Hopmans. 1992. Time domain reflectometry calibration for uniformly and nonuniformly wetted sandy and clayey loam soils. Soil Sci. Soc. Amer. J. 56:1341-1345.

Dean, T.J., J.P. Bell, and A.J.B. Baty. 1987. Soil moisture measurement by an improved capacitance technique, Part I. Sensor design and performance. J. Hydrol. (Amst.) 93:67-78.

Delta-T Devices. 2005. User manual for the WET sensor type WET-2, version 1.3. Delta-T Devices, Burwell, Cambridge, England.

Fares, A. and V. Polyakov. 2006. Advances in crop water management using capacitive water sensors. Adv. Agron. 90:43-77.

Ferre, P.A. and G.C. Topp. 2000. Timedomain reflectometry sensor techniques for soil water content measurements and electrical conductivity measurements, p. 277-300. In: H. Baltes, W. Gopel, and J. Hesse (eds.). Sensors update. Vol. 7. Wiley-VCH, Weinheim, Germany.

Ferre, P.A. and G.C. Topp. 2002. Timedomain reflectometry, p. 434-446. In: G.H. Dane and G.C. Topp (eds.). Methods of soil analysis, Part 4: Physical methods. Soil Sci. Soc. Amer., Madison, WI.

Forschungsgesellschaft Landschaftsentwicklung Landschaftsbau. 2008. Richtlinien für die Planung, Ausführung und Pflege von Dachbegrünungen. Richtlinien für Dachbegrünungen. FLL, Bonn, Germany.

Getter, K.L. and D.B. Rowe. 2006. The role of extensive green roofs in sustainable development. HortScience 41:1276-1285.
Greacen, E.L. 1981. Soil water assessment by the neutron method. CSIRO, Melbourne, Australia.

Hilhorst, M.A. 2000. A pore water conductivity sensor. Soil Sci. Soc. Amer. J. 64:1922-1925.

Kargas, G. and P. Kerkides. 2008. Water content determination in mineral and organic porous media by ML2 theta probe. Irrig. Drainage 57:435-449.

Kargas, G., P. Kerkides, P.M. Seyfried, and A. Sgoumbopoulou. 2011. WET sensor performance in organic and inorganic media with heterogeneous moisture distribution. Soil Sci. Soc. Amer. J. 75:1244-1252.

Kargas, G. and K. Soulis. 2012. Performance analysis and calibration of a new low-cost capacitance soil moisture sensor. J. Irrig. Drain. Eng. 138:632-641.

Kotsiris, G., P.A. Nektarios, and A.T. Paraskevopoulou. 2012. Lavandula angustifolia growth and physiology is affected by substrate type and depth when grown under Mediterranean semiintensive green roof conditions. HortScience 47:311-317.

Ledieu, J., P. de Ridder, P. de Clerck, and S. Dautrebande. 1986. A method of measuring soil moisture by time-domain reflectometry. J. Hydrol. (Amst.) 88:319-328.

Morel, P. and J.C. Michel. 2004. Control of the moisture content of growing media by time domain reflectometry (TDR). Agronomie 24:275-279.

Nektarios, P.A., I. Amountzias, I. Kokkinou, and N. Ntoulas. 2011. Green roof substrate type and depth affect the growth of the native species Dianthus fruticosus under reduced irrigation regimens. HortScience 46:1208-1216.

Nemali, K., F. Montesano, S. Dove, and M. van Iersel. 2007. Calibration and performance of moisture sensors in soilless substrate: $\mathrm{ECH}_{2} \mathrm{O}$ and Theta probe. Sci. Hort. 112:227-234.

Noborio, K., K.J. McInnes, and J.L. Heilman. 1994. Field measurements of soil electrical conductivity and water content by time-domain reflectometry. Comput. Electron. Agr. 11:131-142.

Ntoulas, N., P.A. Nektarios, K. Spaneas, and N. Kadoglou. 2012. Semi-extensive green roof substrate type and depth effects on Zoysia matrella 'Zeon' growth and drought tolerance under different irrigation regimens. Acta Agr. Scand. B Soil Plant Sci. 62:165-173.

Regalado, C., A. Ritter, and R.M. Rodriguez-Gonzalez. 2007. Performance of the commercial WET capacitance 
sensor as compared with time domain reflectometry in volcanic soils. Vadose Zone J. 6:244-254.

Robinson, D.A., C.M.K. Gardner, and J.D. Cooper. 1999. Measurement of relative permittivity in sandy soils using TDR, capacitance and theta probes: Comparison, including the effects of bulk soil electrical conductivity. J. Hydrol. (Amst.) 223:198-211.

Robinson, D.A., S.B. Jones, J.M. Wraith, D. Or, and S.P. Friedman. 2003. A review of advances in dielectric and electrical conductivity measurements in soils using time domain reflectometry. Vadose Zone J. 2:444-475.

Roth, K., R. Schulin, H. Fluhler, and W. Attinger. 1990. Calibration of time domain reflectometry for water content measurement using a composite dielectric approach. Water Resour. Res. 26:22672273.

Rowe, D.B., M.A. Monterusso, and C.L. Rugh. 2006. Assessment of heat-expanded slate and fertility requirements in green roof substrates. HortTechnology 16: $471-477$

Scoggins, H.L. and M. van Iersel. 2006. In situ probes for measurement of electrical conductivity of soilless substrates: Effects of temperature and substrate moisture content. HortScience 41:210-214.

Seyfried, M.S. and M.D. Murdock. 2001. Response of a new soil water sensor to variable soil, water content, and temperature. Soil Sci. Soc. Amer. J. 65:28-34.

Seyfried, M.S., L.E. Grant, E. Du, and K. Humes. 2005. Dielectric loss and calibration of the hydra probe soil water sensor. Vadose Zone J. 4:1070-1079.

Seyfried, M.S. and M.D. Murdock. 2004. Measurement of soil water content with a $50-\mathrm{MHz}$ soil dielectric sensor. Soil Sci. Soc. Amer. J. 68:394-403.

Spaans, E.J.A. and J.M. Baker. 1996. The soil freezing characteristic: Its measurement and similarity to the soil moisture characteristic. Soil Sci. Soc. Amer. J. 60:13-19.

Spectrum Technologies. 2009. Field Scout TDR300, product manual. Spectrum Technologies, Plainfield, IL.

Topp, G.C., J.L. Davis, and A.P. Annan. 1980. Electromagnetic determination of soil water content: Measurements in coaxial transmission lines. Water Resour. Res. 16:574-582.
Topp, G.C., S. Zegelin, and I. White. 2000. Impacts of the real and imaginary components of relative permittivity on time domain reflectometry measurements in soils. Soil Sci. Soc. Amer. J. 64:12441252 .

van Iersel, M., S. Dove, and S. Burnet. 2011. The use of soil moisture probes for improved uniformity and irrigation control in greenhouses. Acta Hort. 893:1049-1056.

White, I., J.H. Knight, S.J. Zegelin, and G.C. Topp. 1994. Comments on 'Considerations on the use of time-domain reflectometry (TDR) for measuring soil water content' by W.R. Whalley. Eur. J. Soil Sci. 45:503-508.

Yoshikawa, K., P.P. Overduin, and J.W. Harden. 2004. Moisture content measurements of moss (Sphagnum spp.) using commercial sensors. Permafrost Periglacial Proc. 15:309-318.

Young, M.H., J.B. Fleming, P.J. Wierenga, and A.W. Warrick. 1997. Rabid laboratory calibration of time domain reflectometry using upward infiltration. Soil Sci. Soc. Amer. J. 61:707-712. 